\title{
The use of alarm pheromones to enhance bait harvest by grass-cutting ants
}

\author{
W.O.H. Hughes* and D. Goulson \\ Biodiversity and Ecology Division, School of Biological Sciences, \\ University of Southampton, Bassett Crescent East, Southampton, \\ SO16 7PX, UK
}

\begin{abstract}
The enhancement of bait for the control of grass-cutting ants was investigated using two species of grass-cutting ant, Atta bisphaerica (Forel) and Atta capiguara (Gonçalves) (Hymenoptera: Formicidae). Bait was applied in loose piles to obtain a direct relationship between ant attraction and bait harvest. Enhancement with alarm pheromone compounds significantly increased the attractiveness and harvest of bait under certain conditions. A large proportion of the ants attracted to the enhanced bait were minor workers. These ants rarely transport bait because of their small size, and so it may be possible to increase the effect of bait enhancement by using smaller bait granules. Foragers of $A$. capiguara were less inclined to transport citrus-pulp bait than were those of Atta laevigata (Fr. Smith), a species that also harvests dicotyledonous plants. This emphasizes the importance of developing a bait matrix that is more acceptable to grass-cutting species. Nevertheless, the results suggest that alarm pheromone compounds have significant potential to improve the efficacy of baits for the control of grass-cutting ants.
\end{abstract}

\section{Introduction}

Leaf-cutting ants (Hymenoptera: Formicidae: Attini: Atta and Acromyrmex) are important economic pests of the neotropics. Between 12 and $17 \%$ of the total herbivory in some areas can be attributed to leaf-cutting ants (Cherrett, 1989 ) and this can rise to $50 \%$ in agroecosystems (Blanton \& Ewel, 1985). Ten of the 28 species of Atta and Acromyrmex have specialized in foraging on monocotyledonous plants and are termed grass-cutting ants (Fowler et al., 1986). These species are significant pests of pasture in South America, as well as of monocotyledonous crops such as sugarcane (Fowler et al., 1986; Precetti et al., 1988; Della Lucia, 1997). It has been estimated that one grass-cutting species, Atta capiguara (Gonçalves), at normal nest densities can reduce the number of head of cattle that an area can support by 10-30\% (Fowler et al., 1986).

*Present address and address for correspondence: Zoological Institute, Department of Population Ecology, University of Copenhagen, Universitetsparken 15, 2100

Copenhagen, Denmark

Fax: +4535321250

E-mail: WOHHughes@zi.ku.dk
The most common method of leaf-cutting ant control at present is the use of toxic baits (Vilela, 1986; Della Lucia, 1997). These can be distributed near the ant nest or in areas where damage is occurring, and have a slow acting insecticide formulated in a matrix of citrus pulp. The ants transport the baits back to the nest where the toxin circulates throughout the colony (Echols, 1966). Such baits can be extremely effective against species that forage on dicotyledonous plants (Zanuncio et al., 1992; 1996; Della Lucia, 1997). However, grass-cutting ants are only mildly attracted to citrus pulpbased baits and such baits are of low efficacy against these species (Fowler et al., 1986; Lapointe et al., 1993; Zanuncio et al., 1993; Della Lucia, 1997; personal observation). There is therefore a significant need for the development of baits that are more attractive to grass-cutting ants.

One possible method of increasing the attractiveness of baits is pheromone enhancement. Communication in leafcutting ants relies primarily upon the use of pheromones and a number of these have attractive properties. The incorporation of the attractive components from one or more of these pheromones could therefore enhance the attractiveness and harvest of bait. Several candidate pheromones have been examined with this view in mind, but without success. Robinson \& Cherrett (1974) applied a range 
of brood extracts to filter paper discs but failed to find any improvement in transport back to the nest by Atta cephalotes (Linnaeus). Possibly the pheromone with the most obvious potential as a bait enhancer is the trail pheromone, and the main components of this have been tested in both laboratory and the field experiments with Atta sexdens (Linnaeus), A. cephalotes and Acromyrmex octospinosus (Reich) (Robinson \& Cherrett, 1978; Robinson et al., 1982; Vilela \& Howse, 1988). Although trail pheromone compounds did improve the discovery and transport of filter paper discs that were not inherently attractive, they did not enhance citrus pulp bait, presumably because it was already attractive to these species. The leaf-marking pheromone of Atta cephalotes has also been examined, but no improvement in bait transport was found for probably the same reason (Vilela \& Howse, 1988; Howse, 1990). However, components from the alarm pheromone have been found to show some potential. Leaf-cutting ants exhibit an aggressive alarm reaction during which they release an alarm pheromone from their mandibular glands (Blum et al., 1968; Moser et al., 1968; Knapp, 1995). One of the main behavioural responses of the ants to their alarm pheromone is attraction to the source (Moser et al., 1968; Hughes et al., 2001a). Experiments with Acromyrmex octospinosus (Knapp, 1987) and Atta sexdens rubropilosa (Forel) (Knapp, 1995) have found that enhancement with certain alarm pheromone components can improve the discovery and harvest of baits by these species.

The compositions of the alarm pheromones of two grasscutting species, Atta bisphaerica Forel and A. capiguara, have recently been established (Hughes et al., 2001b) and the main behaviourally-active component found to be 4-methyl-3heptanone (Hughes et al., 2001a). When this compound was added to bait sealed inside plastic sachets that the ants could readily cut open, it was found to substantially increase the attractiveness of the bait (Hughes et al., in press). However, there was not found to be any improvement in bait harvest. In the present study, bait was applied in loose piles to obtain a more rapid response that was predicted to result in a closer relationship between ant attraction and bait harvest than that exhibited when bait is applied in sealed sachets. A series of experiments with A. bisphaerica and A. capiguara were carried out in an attempt to obtain an enhancement of bait harvest and to examine the reasons why such an improvement may not occur. Although 4-methyl-3heptanone is the most behaviourally-active component, it is not as active as the natural alarm pheromone (Hughes et al., 2001a), and while an alarm response can occur at some distance along the trail the response is greatest close to the entrance hole (Hughes \& Goulson, 2001). Various source/ position combinations of 4-methyl-3-heptanone and natural alarm pheromone were tested at positions near the entrance and further along the trail. The response of $A$. capiguara was also compared with that of a generalist species, Atta laevigata (F. Smith), which is known to harvest citrus pulp baits readily.

\section{Materials and methods}

All of the following experiments were carried out between March and May 1998. Replicates with A. bisphaerica were carried out near Viçosa, Minas Gerais, and Botucatu, São Paulo, in Brazil. The experiments with A. capiguara and A. laevigata used nests located near Botucatu and near Capinópolis, Minas Gerais. Only trails with good activity (at least 25 ants per minute) from mature nests were used. Bait was placed at two positions during these experiments: $10 \mathrm{~cm}$ to one side of the trail entrance hole ('near entrance' position) and $10 \mathrm{~cm}$ to one side of the trail at a point $1 \mathrm{~m}$ from the entrance hole ('trail' position). The general experimental method involved $10 \mathrm{~cm}$ diameter circles being cleared of vegetation at the position to be tested, $24 \mathrm{~h}$ prior to usage. One hundred granules of Mirex-S bait $\left(3 \mathrm{~g} \mathrm{~kg}^{-1}\right.$ ai sulfluramid) (Attakill, São Paulo, Brazil) were placed in a pile at the centre of the $10 \mathrm{~cm}$ diameter circle. Only full size granules were used (approximately $7 \mathrm{~mm}$ length, $2 \mathrm{~mm}$ diameter and $35 \mathrm{mg}$ weight). An alarm source was then immediately placed on top of the pile at its centre. Alarm sources were either $10 \mu \mathrm{l}$ of 4-methyl-3-heptanone (racemic, 99\% purity, ChemSampCo, South Carolina, USA) loaded on to a cigarette filter, or a crushed ant head. Although it is the $S$ enantiomer that is thought to be found in Atta species, the behavioural response is not inhibited by the presence of the $R$ enantiomer (Riley et al., 1974; Nascimento et al., 1997). Where crushed heads were used, a forager with an estimated head width of between 2.5 and $3.0 \mathrm{~mm}$ was removed from the trail using forceps. The head was separated from the body, placed at the centre of the bait pile, and crushed using the forceps. The forceps were cleaned in dichloromethane and the solvent allowed to evaporate prior to usage. Bait piles with a blank cigarette filter were used as controls. Enhanced and control bait piles were tested on separate trails from the same nest.

\section{Pheromone enhancement of bait piles}

Three source/ position combinations were tested with $A$. bisphaerica to establish if any resulted in an enhancement of attraction or harvest: crushed ant head at the trail position (replicated 11 times), 4-methyl-3-heptanone at the trail position (replicated 11 times), and 4-methyl-3-heptanone at the near entrance position (replicated 19 times). Following the results of the A. bisphaerica replicates, two of the source/position combinations were tested with A. capiguara: crushed ant head at the trail position (replicated 24 times) and 4-methyl-3-heptanone at the near entrance position (replicated 10 times).

Instantaneous counts were made of the number of ants within the circles $5 \mathrm{~min}$ after application of the bait and source. The ant counts were $\log (x+1)$ transformed and the numbers at the test and control piles compared with $t$-tests. Ants counted were classified as either minor workers (estimated head width $<1.4 \mathrm{~mm}$ ) or foragers (estimated head width $>1.4 \mathrm{~mm}$ ). The proportions of the ants counted that were minor workers were compared using $G$ tests, with $G$ adjusted with William's correction factor because there was only one degree of freedom (Fowler \& Cohen, 1990). The numbers of bait granules remaining within the circles were counted at $45 \mathrm{~min}$ after application and compared using $t$-tests.

\section{Detailed comparison of the response of A. capiguara and A. laevigata}

In this experiment crushed ant heads were used as the sources and placed at the trail position as before. Both tests and controls were replicated five times with each species. Instantaneous counts of the number of ants within the circles were made prior to application. In the A. capiguara replicates, 
counts were then made at 2, 5, 15, 30 and 45 min after application. When $A$. laevigata was tested they were only made at 2, 5 and $10 \mathrm{~min}$ after application because all the bait had been harvested by this time. In addition, the total numbers of ants that contacted the bait and the numbers that transported the bait were recorded during the 2 min preceding each count. Ants that touched the pile of bait granules in any way were recorded as having 'contacted' it. When an ant then grasped a bait granule between its mandibles, and, either by lifting or dragging, moved it out of the $10 \mathrm{~cm}$ circle, it was recorded as having 'transported' the bait. Separate counts were made for foragers and minor workers.

The numbers of ants responding to the control and test bait piles were $\log (x+1)$ transformed and analysed with a repeated measures ANOVA. The proportions of foragers and minors in the ants responding were compared with G-tests, as were the proportions of ant contacts that transported the bait.

\section{Results}

\section{Pheromone enhancement of bait piles}

All of the source/position combinations resulted in significantly more ants being attracted to the enhanced bait piles than to the control piles (fig. 1). Of the combinations tested with $A$. bisphaerica, 4-methyl-3-heptanone at the trail position provided the smallest improvement and so this combination was not tested with $A$. capiguara. In every case, a greater proportion of the ants responding at the enhanced piles were minor workers compared with those at the control piles (fig. 2). In all of the source/position combinations more bait was harvested from the test piles than from the controls (fig. 3). This difference was only statistically significant when the bait was enhanced with 4methyl-3-heptanone and placed at the near entrance position, although it was just marginally non-significant when enhanced with crushed heads and placed by $A$. bisphaerica trails $(P=0.052)$. Power analysis of the latter source/position combination reveals that there was only a $50 \%$ probability of not making a type II error and the sample size would have had to be doubled to increase the power to $80 \%$. Overall, $40-57 \%$ of the control bait piles were harvested, and $57-89 \%$ of the test piles.

\section{Detailed comparison of the response of $\mathrm{A}$. capiguara and A. laevigata}

The reaction of $A$. capiguara to the bait piles was as previously described, with significantly more ants being attracted to the enhanced bait $\left(F_{5,40}=13.2, P<0.001\right)$ (fig. $\left.4 a\right)$. Treatment did not significantly affect the change in the number of $A$. laevigata workers near the bait during the experiment $\left(F_{3,24}=1.07, P=0.38\right)$ (fig. $\left.4 \mathrm{~b}\right)$. Numbers at the test and control piles were not significantly different $\left(F_{1,8}=\right.$ $0.54, P=0.48)$, and increased significantly at both $\left(F_{3,24}=50.2\right.$, $P<0.001)$. In both species, a significantly greater proportion of the ants attracted to the test piles were minors compared to the controls (A. capiguara: $79.5 \pm 5.9 \%$ vs. $58.9 \pm 14.9 \%, G_{a d i}=$ 11.0, $d f=1, P<0.001$; A. laevigata: $43.5 \pm 5.6 \%$ vs. $24.3 \pm 4.6 \%$, $\left.G_{a d j}=19.3, d f=1, P<0.001\right)$. Overall, foragers were more likely than minor workers to transport bait (A. capiguara: $G_{a d j}$ = 136.6, $d f=1, P<0.001 ;$ A. laevigata: $G_{a d j}=294.8, d f=1, P<$ 0.001 ) (fig. 5). Minors of $A$. capiguara only transported bait in

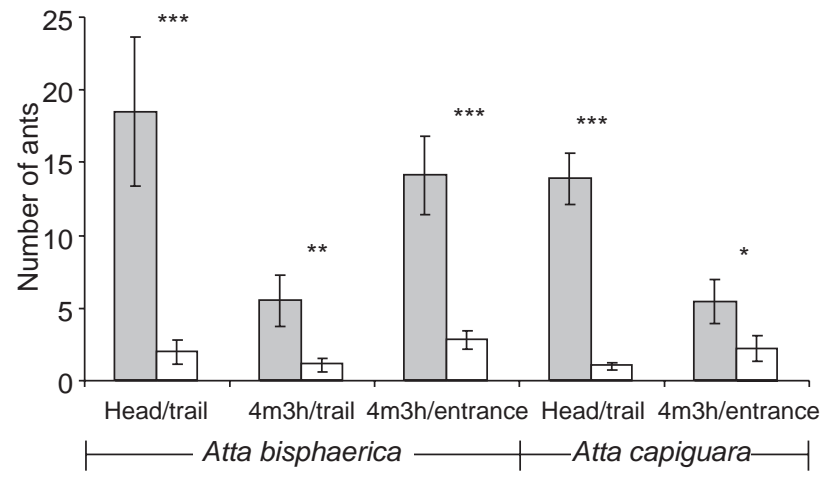

Fig. 1. Response to bait piles during the first experiment. Three source/position combinations were tested: crushed head/trail, 4-methyl-3-heptanone/trail, and 4-methyl-3-heptanone/near entrance. Bait piles were either enhanced with the alarm source $(\square)$, or were unenhanced $(\square) .\left({ }^{\star} P<0.05 ;{ }^{* *} P<0.01\right.$; ${ }^{* * *} P<0.001$; ns, $P>0.05$; $t$-tests.)

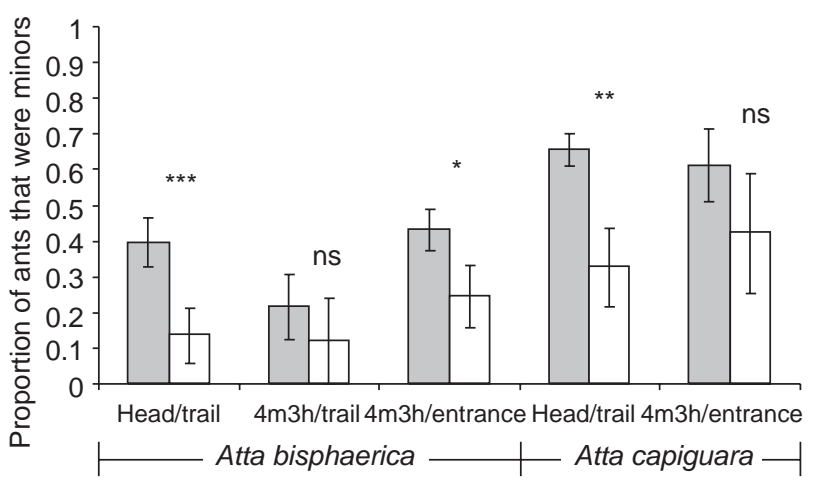

Fig. 2. Proportions of ants responding to bait piles during the first experiment that were minor workers. Three source/position combinations were tested: crushed head/trail, 4-methyl-3heptanone/trail, and 4-methyl-3-heptanone/near entrance. Bait piles were either enhanced with the alarm source $(\square)$, or were unenhanced $(\square)$. ( ${ }^{*} P<0.05,{ }^{* *} P<0.01$; ${ }^{* *} P<0.001$; ns, $P>0.05$; G-tests.)

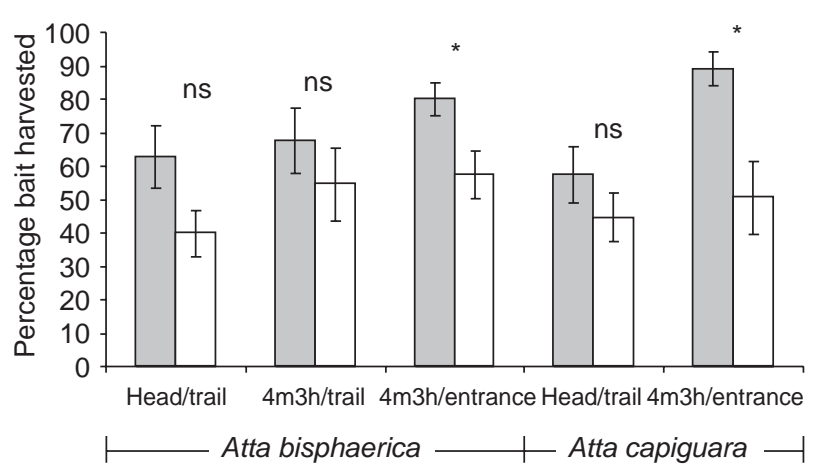

Fig. 3. Bait harvested after $45 \mathrm{~min}$. Three source/position combinations were tested: crushed head/trail, 4-methyl-3heptanone/trail, 4-methyl-3-heptanone/near entrance. They were either enhanced with the alarm source $(\square)$, or were unenhanced ( $\square)$. ( ${ }^{*} P<0.05 ;{ }^{* *} P<0.01$; ${ }^{* *} P<0.001$; ns, $P>0.05$; $t$-tests.) 

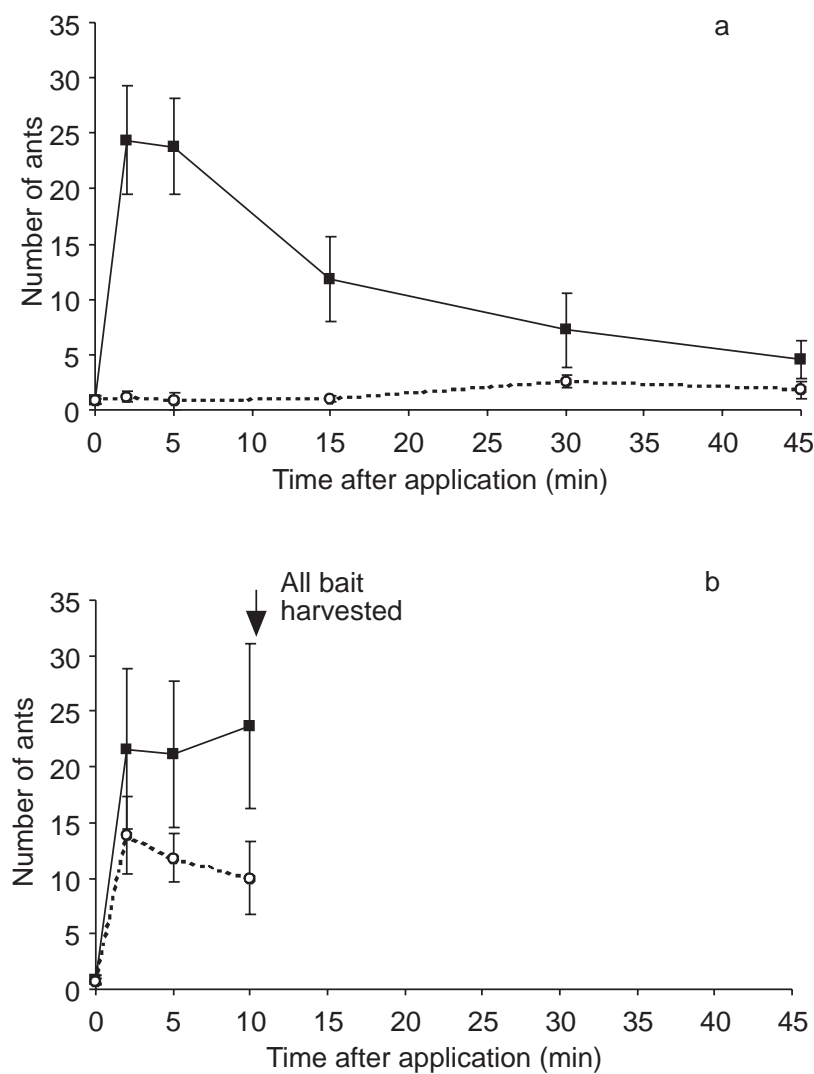

Fig. 4. Numbers of (a) Atta capiguara, and (b) A. laevigata, ants responding to bait piles during the second experiment. Bait piles were placed at the trail position and were either enhanced with a crushed head (---) or left unenhanced (--o-).

less than $5 \%$ of contacts. Ants contacting the bait were more likely to transport it if it was not associated with alarm pheromone (A. capiguara: $G_{a d j}=35.2, d f=1, P<0.001 ; A$. laevigata: $\left.G_{\text {adj }}=153.1, d f=1, P<0.001\right)$. The most obvious difference between the species was the harvest of bait. All of the bait was harvested by A. laevigata within $10 \mathrm{~min}$ of application. Even $45 \mathrm{~min}$ after application an average of about $50 \%$ of the A. capiguara bait remained, with harvesting still in progress. Atta laevigata foragers were significantly more likely than $A$. capiguara foragers to transport bait they contacted $\left(G_{a d j}=11.5, d f=1, P<0.001\right)$ (fig. 5).

\section{Discussion}

Enhancement of bait piles either with 4-methyl-3heptanone or with crushed ant heads resulted in significantly greater numbers of ants being attracted to them than to unenhanced bait piles. The alarm response stimulated was similar to that described previously for various species of Atta (Blum et al., 1968; Moser et al., 1968; Knapp, 1995; Hughes et al., 2001a) and in agreement with results obtained previously using bait in sachets (Hughes et al., in press). In both A. bisphaerica and A. capiguara, crushed heads resulted in a greater response than that stimulated by 4-methyl-3-heptanone. The alarm pheromone of leaf-cutting ants is made up of a complex mixture of compounds (Nascimento et al., 1993; Hernández et al., 1999; Hughes et al., 2001b). Although 4-methyl-3-heptanone is the most
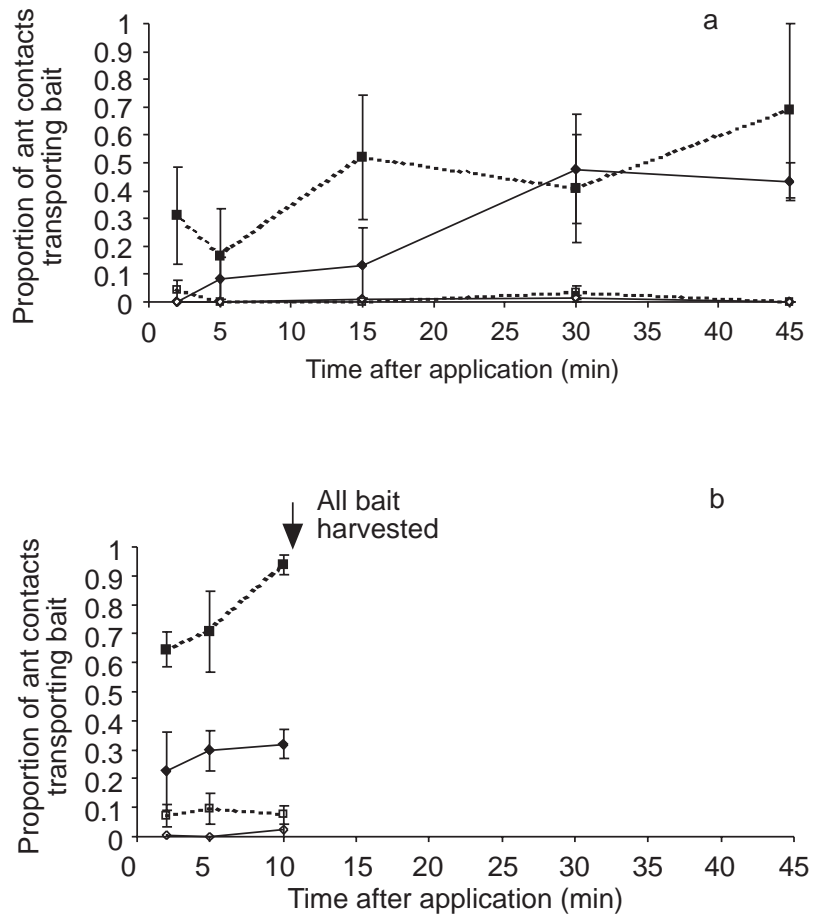

Fig. 5. Proportions of (a) Atta capiguara, and (b) A. laevigata, ant contacts with bait that resulted in a bait granule being transported during the second experiment. Bait piles were placed at the trail position and were either enhanced with a crushed head $(-\bullet-$, foragers; $-\diamond-$, minors) or left unenhanced (----, foragers; -----, minors).

behaviourally-active component in every species of Atta examined, the complete alarm pheromone produced by crushed ant heads stimulates a greater response than does 4methyl-3-heptanone alone (Hughes et al., 2001a). It would therefore appear that by incorporating other components of the alarm pheromone together with 4-methyl-3-heptanone, it may be possible to obtain a greater improvement in bait attraction than that stimulated by the ketone alone.

Unlike most previous attempts to enhance leaf-cutting ant baits with pheromones (Robinson \& Cherrett, 1974, 1978; Robinson et al., 1982; Vilela \& Howse, 1988; Hughes et al., in press), these experiments with bait piles found an improvement in bait harvest. The application of natural alarm pheromone with bait piles at $1 \mathrm{~m}$ along the trail resulted in a substantial but non-significant increase in harvest, although the power of the test with $A$. bisphaerica was low. However, the addition of 4-methyl-3-heptanone to bait piles applied near the entrance holes caused a significant increase in harvest by both $A$. bisphaerica and $A$. capiguara. In this treatment, $80.0 \%$ of the enhanced bait was harvested by $A$. bisphaerica (compared with $57.4 \%$ of the control bait), and $89.1 \%$ by $A$. capiguara (compared with $50.5 \%$ of the control bait). As proportions of the quantity harvested from the unenhanced piles, enhancement with 4methyl-3-heptanone resulted in $39.4 \%$ more bait being harvested by $A$. bisphaerica and $76.6 \%$ more by $A$. capiguara.

In spite of the significance of these results, they do raise the question of why the effect of enhancement on bait 
harvest was not even greater. Enhancement resulted in as much as ten times as many ants being attracted to the enhanced bait as to the controls, yet the level of harvest was only $39-76 \%$ greater at most. Minor workers are the main group of ants to respond to alarm pheromone and are not normally involved in the harvest of food (Stradling, 1978; Wilson, 1980; Hughes \& Goulson, 2001). These ants were found to be less inclined to transport bait particles than their larger nestmates. However, this may be at least partly due to the size of the granules which were very large relative to the size of the minor workers, and therefore difficult for these ants to manipulate. Minor workers will transport pieces of vegetation that are small enough for them to manipulate, although this is rare (Hughes \& Goulson, 2001; personal observation). The use of granules small enough for minor workers to transport may therefore increase the effect of enhancement on bait harvest.

In addition, the ants attracted to bait by an alarm pheromone compound will inherently be alarmed. The results of the second experiment showed that alarmed ants are less likely to transport bait than unalarmed individuals. This negative effect though, is not necessarily as problematic as it appears. The level of alarm can decrease quite rapidly (Hughes et al., 2001a), so the pick-up rate would be expected to increase in a corresponding manner. Such an increase in the pick-up rate over time by $A$. capiguara foragers was seen at the enhanced bait piles, with the proportion of contacts by foragers that resulted in bait being transported being the same at the test and control piles after $30 \mathrm{~min}$. In the $A$. laevigata replicates all the bait was harvested within $10 \mathrm{~min}$. The large difference between the test and control piles in the proportion of A. laevigata foragers contacting the bait that then transported it suggests that this was too short a time span for a sufficient decline in alarm behaviour to have occurred. The effect of alarmed ants being less likely to harvest bait appears to be outweighed by the benefit gained from attracting a larger number of ants to the bait more quickly.

When the response of $A$. capiguara to loose bait piles was compared with that of $A$. laevigata, an important difference emerged. Atta laevigata harvests both monocotyledonous and dicotyledonous plants (Cherrett, 1986; Fowler et al., 1986), and will readily harvest baits based upon a citrus pulp matrix. Ants of this species were attracted in large numbers even to the unenhanced bait and were far more likely to transport bait than $A$. capiguara. As a result the bait was harvested considerably quicker by A. laevigata. This clearly shows the importance of using bait based on a matrix that is acceptable to the species concerned. In fact, harvest of the control piles by $A$. laevigata was so rapid that no improvement due to the increased attractiveness of enhanced bait could be detected.

In conclusion, the results presented here demonstrate that the addition of a source of either natural alarm pheromone or 4-methyl-3-heptanone alone can increase the attractiveness of bait piles to A. bisphaerica and A. capiguara. They also establish that such an improvement in attractiveness can produce a significant increase in bait harvest. Although this improvement was only statistically significant when bait was applied close to the trail entrance, this was partly due to the small number of replicates and the relative crudity of the experiments. It is highly likely that the effect can be considerably improved by measures such as the use of smaller bait granules, the incorporation of additional compounds from the alarm pheromone together with 4methyl-3-heptanone, or by the development of a bait matrix that is more acceptable to grass-cutting ant species. Enhancement of bait with alarm pheromone compounds therefore has significant potential to substantially improve the harvest of bait by A. bisphaerica and A. capiguara, and probably other species of Atta as well.

\section{Acknowledgements}

The authors would like to thank John Bradshaw, Malcolm Cherrett, Jason Chapman and two anonymous referees for commenting on earlier versions of this work. Facilities at the Universidade Federal de Viçosa were kindly provided by Evaldo Vilela and at Universidade Estadual Paulista in Botucatu by Luiz Forti. We are also grateful to Juliane Lopes for assistance with the fieldwork. Funding for this study was provided by Griffin Corporation, Georgia, USA.

\section{References}

Blanton, C.M. \& Ewel, J.J. (1985) Leaf-cutting ant herbivory in successional and agricultural tropical ecosystems. Ecology 66, 861-869.

Blum, M.S., Padovani, F. \& Amante, E. (1968) Alkanones and terpenes in the mandibular glands of Atta species (Hymenoptera: Formicidae). Comparative Biochemistry and Physiology 26, 291-299.

Cherrett, J.M. (1986) The biology, pest status and control of leafcutting ants. Agricultural Zoology Reviews 1, 1-37.

Cherrett, J.M. (1989) Leaf-cutting ants. pp. 473-488 in Lieth, H. \& Werger, M.J.A. (Eds) Ecosystems of the world 14B: tropical rainforest ecosystems. Biogeographical and ecological studies. Amsterdam, Elsevier Press.

Della Lucia, T.M.C. (1997) Leaf-cutting ant control in Brazil: state of the art. pp. 147-151 in Delabie, J.H.C., Campiolo, S., Nascimento, I.C. \& Mariano, C.S.F. (Eds) Mirmecologia tropical. VI International Pest Ant Symposium, XIII Encontro de Mirmecologia. Ilhéus, Brazil.

Echols, H.W. (1966) Assimilation and transfer of mirex in colonies of Texas leaf-cutting ants. Journal of Economic Entomology 59, 1336-1338.

Fowler, H.G., Forti, L.C., Pereira-da-Silva, V. \& Saes, N.B. (1986) Economics of grass-cutting ants. pp. 28-35 in Lofgren, C.S. \& Vander Meer, R.K. (Eds) Fire ants and leafcutting ants: biology and management. Boulder, Colorado, Westview Press.

Fowler, J. \& Cohen, L. (1990) Practical statistics for field biology. Chichester, John Wiley and Sons.

Hernández, J.V., Cabrera, A. \& Jaffe, K. (1999) Mandibular gland secretion in different castes of the leaf-cutter ant Atta laevigata. Journal of Chemical Ecology 25, 2433-2444.

Howse, P.E. (1990) Pheromonal control of behaviour in leafcutting ants. pp. 427-437 in Vander Meer, R.K., Jaffé, K. \& Cedeno, A. (Eds) Applied myrmecology: a world perspective. Boulder, Colorado, Westview Press.

Hughes, W.O.H. \& Goulson, D. (2001) Polyethism and the importance of context in the alarm reaction of the grasscutting ant, Atta capiguara. Behavioural Ecology and Sociobiology 49, 503-508.

Hughes, W.O.H., Howse, P.E. \& Goulson, D. (2001a) The response of grass-cutting ants to natural and synthetic versions of their alarm pheromone. Physiological Entomology 26, 165-172. 
Hughes, W.O.H., Howse, P.E. \& Goulson, D. (2001b) The mandibular gland chemistry of grass-cutting ants: species, caste and colony variation. Journal of Chemical Ecology 27, 109-124.

Hughes, W.O.H., Howse, P.E., Vilela, E.F., Knapp, J.J. \& Goulson, D. A field evaluation of the potential of alarm pheromone compounds to enhance baits for the control of grass-cutting ants. Journal of Economic Entomology, in press.

Knapp, J.J. (1987) Studies of the foraging behaviour of the leafcutting ant Acromyrmex octospinosus (Reich) in Guadeloupe. MSc thesis, University of Southampton, UK.

Knapp, J.J. (1995) Chemical aspects of communication and defence in leaf-cutting ants. PhD thesis, University of Southampton, UK.

Lapointe, S.L., Serrano, M.S. \& Villegas, A. (1993) Colonization of two tropical forage grasses by Acromyrmex landolti (Hymenoptera: Formicidae) in eastern Colombia. Florida Entomologist 76, 358-365.

Moser, J.C., Brownlee, R.C. \& Silverstein, R. (1968) Alarm pheromones of the ant Atta texana. Journal of Insect Physiology 1, 529-535.

Nascimento, R.R., Morgan, E.D., Billen, J., Schoeters, E., Della Lucia, T.M.C. \& Bento, J.M. (1993) Variation with caste of the mandibular gland secretion in the leaf-cutting ant Atta sexdens rubropilosa. Journal of Chemical Ecology 19, 907-918.

Nascimento, R.R., Morgan, E.D., König, W.A. \& Della Lucia, T.M.C. (1997) Absolute configuration of 4-methyl-3heptanone and 4-methyl-3-heptanol from mandibular glands of virgin males and females of Atta sexdens rubropilosa. Journal of Chemical Ecology 23, 1569-1575.

Precetti, A.A.C.M., Nasato, A.C.M., Beltrame, G.J., Oliveira, J.E. \& Junior, M.P. (1988) Perdas de produção em cana-deaçúcar, causadas pela saúva-mata-pasto, Atta bisphaerica. Parte I. Boletin Technico do Coopersucar 42, 25-30.

Riley, R.G., Silverstein, R.M. \& Moser, J.C. (1974) Isolation, identification, synthesis and biological activity of volatile compounds from the head of Atta ants. Journal of Insect Physiology 20, 1629-1637.

Robinson, S.W. \& Cherrett, J.M. (1974) Laboratory investigations to evaluate the possible use of brood pheromones of the leaf-cutting ant Atta cephalotes (L.) (Formicidae, Attini) as a component in an attractive bait. Bulletin of Entomological Research 63, 519-529.
Robinson, S.W. \& Cherrett, J.M. (1978) The possible use of methyl 4-methylpyrrole-2-carboxylate, an ant trail pheromone, as a component of an improved bait for leafcutting ant (Hymenoptera: Formicidae) control. Bulletin of Entomological Research 68, 159-170.

Robinson, S.W., Jutsum, A.R., Cherrett, J.M. \& Quinlan, R.J. (1982) Field evaluation of methyl 4-methylpyrrole-2carboxylate, an ant trail pheromone, as a component of baits for leaf-cutting ant (Hymenoptera: Formicidae) control. Bulletin of Entomological Research 72, 345-356.

Stradling, D.J. (1978) The influence of size on foraging in the ant, Atta cephalotes, and the effect of some plant defence mechanisms. Journal of Animal Ecology 47, 173-188.

Vilela, E.F. (1986) Status of leaf-cutting ant control in forest plantations in Brazil. pp. 159-171 in Lofgren, C.S. \& Vander Meer, R.K. (Eds) Fire ants and leaf-cutting ants: biology and management. Boulder, Colorado, Westview Press.

Vilela, E.F. \& Howse, P.E. (1988) Pheromone performance as an attractive component in baits for the control of the leafcutting ant Atta sexdens rubropilosa Forel, 1908 (Hymenoptera: Formicidae). Anais da Sociedade de Entomologia do Brasil 17, 107-124.

Wilson E.O. (1980) Caste and division of labour in leaf-cutter ants (Hymenoptera: Formicidae: Atta). II. The ergonomic optimization of leaf cutting. Behavioral Ecology and Sociobiology 7, 157-165.

Zanuncio, J.C., Couto, L., Santos, G.P. \& Zanuncio, T.V. (1992) Eficiência da isca granulada Mirex-S, à base de sulfluramid, no controle da formiga cortadeira Atta laevigata (F. Smith, 1858) (Hymenoptera: Formicidae). Revista Árvore 16, 357-361.

Zanuncio, J.C., Couto, L., Zanuncio, T.V. \& Fagundes, M. (1993) Eficiência da isca granulada Mirex-S (sulfluramida 0,3\%) no controle da formiga-cortadeira Atta bisphaerica Forel (Hymenoptera: Formicidae). Revista Árvore 17, 85-90.

Zanuncio, J.C., Laranjeiro, A.L. \& DeSouze, O. (1996) Controle de Acromyrmex subterraneus molestans Santschi (Hymenoptera: Formicidae) com sulfluramida. Anais da Sociedade de Entomologia do Brasil 25, 383-388.

(Accepted 6 February 2002)

(C) CAB International, 2002 